\title{
A New Approach to the Definitions and Relations of the Concepts of Mathematics, Eternity, Infinity, Death, Time and the First Point
}

Nasip Demirkuş* and Enes Abdurrahman Bilgin

Department of Mathematics and Science, Education Faculty, VanYüzüncü Yıl University, Education Faculty, Van, Turkey

\begin{abstract}
Mathematics is like a habitat in which all the branches of science flourish. Mathematical Science: Creates the denominator of the Science Cluster. Other branches of science form the shares of the Science Cluster. The Sum of shares and denominator: Represents The Cluster of Science. Mathematical knowledge is like the heart of science. Science without mathematics cannot work.

In This Presentation, firstly, the position and definition of mathematics in science will be done. The original definitions of eternity, infinity, death, time and first point concepts and their relations will be given. Later, these concepts will be related to the Big Bang Theory and the Big Rip Theory.
\end{abstract}

Before the The Planck time (10-43 seconds) from the Beginning of Big Bang Theory: The occurrence of time, space, speed and gravitational dimensions will be mathematically related, Information about the starting point of the universe will be given.

Mathematical explanations of 4 basic forces in the universe will be done. There are 4 conventionally accepted fundamental interactions: gravitational, electromagnetic force, strong nuclear force and weak nuclear force.

As a result, the concepts of Eternity, Infinity, Death, Time, and First Point in mathematics will match the equivalents in the universe.

Keywords: Eternity; Infinity; Death; Time; The first point

\section{Introduction}

Under the heading of "Common Conceptions of Eternity" Eternity is explained in 5 categories by Eire, 2010. These are: 1 . Time without a beginning or an end, or sempiternity. 2. A state that transcends time. 3. A state that includes time but precedes and exceeds it. 4. Platonic eternity: the intelligible realm 5 . Relation to infinity [1-6].

"Eternity" elicits very different kinds of treatment from historians than it would from philosophers, theologians, or cosmologists, though historian Eire draws effortlessly on what philosophers and theologians have said, and relates space and time sufficiently to give confidence that he knows something of the bearing of cosmology on his subject. [...] he mentions how "eternity" is often associated with infinity, and hauls in the Oxford English Dictionary to take over the definitions from there [7].

Second, though Philip himself believed that past time was necessarily finite in a created world, this paper will show how his arguments for this position have weaknesses that allowed later thinkers to build upon Philip's distinctions between time and eternity to demonstrate the conceptual possibility of a created world infinite in past duration [8].

Let me briefly contrast this vanishing point of the Being of the Event with the vanishing point of traditional, Renaissance perspective. The latter is located on anever-receding horizon that, if pursued, rounds us back on our initial starting point in other words, it is a figure of infinity. The logical end of Badiou's vanishing point is the subject's point of entry into a new level (universality) that leaps out of (infinite) time into eternityöwhat Badiou calls 'immortality'. It is for this reason that we think it fair to say Badiou's is a vertical, not a horizon-tal perspective. [For more on eternity and vertical time see MacCannell [9].

Thomas Aquinas difference, three types of temporality - time diachronic, eternity and evo - among which the third, employed to designate the chronological measurement of celestial bodies and substances immaterial created, maintains the characteristics of Aristotelian time: Infinity and distinction between before and after [10].

\section{Mathematical Science}

Mathematics is like a habitat in which all the branches of science flourish. Mathematical Science: Creates the denominator of the Science Cluster. Other branches of science form the shares of the Science Cluster. The Sum of shares and denominator: represents The Cluster of Science. Mathematical knowledge is like the heart of science. Science without mathematics cannot work [4,5].

In the wisdom pool, Mathematic is the structure of all energy status and creatures (intellectual, digital, virtual, objective, semi-virtual... etc.) and real relations, with symbols, numbers, equations and clusters.

The definitions of mathematics and science have misconceptions and shortcomings. Expression of science by means of equations, symbols, sets, figures, pictures, etc. is called mathematics. Accordingly, mathematics is not a subdivision of science, but it is like a science interface. With this logic and reasoning movement; the sum of other branches of science outside mathematics refers to the interface of cultural alphabets and experience. In this case (all science branches except mathematics): The cultural and life interface of science can be

*Corresponding author: Nasip Demirkus, Department of Mathematics and Science, Education Faculty, VanYüzüncü Yıl University, Education Faculty, Van, Turkey, Tel: 904445065; E-mail: nasip@hotmail.com

Received July 09, 2018; Accepted August 03, 2018; Published August 07, 2018

Citation: Demirkus N, Bilgin EA (2018) A New Approach to the Definitions and Relations of the Concepts of Mathematics, Eternity, Infinity, Death, Time and the First Point. J Biom Biostat 9: 408. doi: 10.4172/2155-6180.1000408

Copyright: (c) 2018 Demirkuş N, et al. This is an open-access article distributed under the terms of the Creative Commons Attribution License, which permits unrestricted use, distribution, and reproduction in any medium, provided the original author and source are credited. 
tried. The evolutionary interface of science expresses the real life story of all the changes in science. The evolutionary interface refers to the changing science depending on natural and social conditions. With this logic, science has three interfaces. 1. Mathematical interface, 2. Natural, cultural and life interface, 3. Evolutionary (change) interface.

Infinite $(\mathbf{t} \neq \mathbf{0},+\infty,-\infty,|\infty|)$

It is a concept that reaches incalculable dimensions based on human possibilities. Georg Cantor has given many ideas about endless and infinite sets of clusters. In the theory that they develop, there are endless clusters in different dimensions. For example, a set of integers can be counted infinite, The set of real numbers can not be counted infinite.- Every infinite; It is in a restricted or unbounded set. In today's mathematics, the definition and position of this concept is lacking. Acting from this assumption; Every infinite; It is in a restricted or unbounded set.

The world's two-dimensional surface is final, but there is no limit. If you go along a straight line, it will eventually return to its starting point. The universe, at least in principle, can have a similar topology of this type. If so, somebody going on a straight line through the universe will eventually return to the starting point. On the other hand, if the universe has a flat topology instead of leaning like a sphere, it can be both unlimited and infinite. The curvature of the universe is measured by multipolar moments in the cosmic background. Radiation analyzes recorded by the WMAP spacecraft show that the universe has a flat topology. The idea of eternity extends to the multiple universe hypothesis, which is explained by astrophysicist Michio Kaku.

\section{Eternity $(\mathbf{t} \leq-\infty, \mathbf{t} \geq \infty)$}

Eternal is immortal. Eternity is immortal clusters. Speed is bigger than infinity. Speed is eternity. Eternity should not be confused with the notion of infinity. It is called eternity to the real infinity, the life line, that is not influenced by the formation and destruction of the universe, but before and after the destruction, which goes from the plus and minus directions to eternity.

\section{Time dimension}

The time dimension is like the lifetime counter of transient life. Time is an adherence to transient life cycles. As speed increases, time shrinks approaching zero. For example, some meaningful results are interesting when we place the infinite and zero numbers in time in $\mathrm{E}=\mathrm{M}$. $[\mathrm{L}(\text { Space }) / \mathrm{T} \text { (Time) }]^{2}$.

$$
\begin{aligned}
& \mathrm{E}(\text { Energy })=\mathrm{M}\left(\text { Mass). } \mathrm{C}^{2}\right. \text { (Light Speed) } \\
& \mathrm{E}=\mathrm{M} .[\mathrm{L}(\text { Space }) / \mathrm{T}(\text { Time })]^{2} \\
& \mathrm{E}=\mathrm{M}[\mathrm{L} /+\infty,-\infty, \infty \geq, \leq \infty,|\infty|, 0]^{2} .
\end{aligned}
$$

\section{Space dimension}

The classical space: is defined as three-dimensional (intersection $\mathrm{x}$, $y$, and $\mathrm{z}$ coordinates). Perhaps, the smallest temporary space is the first space cluster/first cosmic point. However, this first space (first cluster); A very small moment has also expanded at a faster rate than the speed of light (Inflation Theory). The infant photo of the universe is displayed.

http://www.biyolojiegitim.yyu.edu.tr/fizuzaypdf/paralel2010.pdf

http://www.biyolojiegitim.yyu.edu.tr/f/yaradiliss.pdf

$\mathrm{E}($ Energy $)=\mathrm{M}$ (Mass). $\mathrm{C}^{2}$ (Light Speed)

$\mathrm{E}=\mathrm{M} .[\mathrm{L}(\text { Space }) / \mathrm{T}(\text { Time })]^{2}$
$\mathrm{E}=\mathrm{M} .[+\infty,-\infty, \infty \geq, \leq \infty,|\infty|, 0 / \mathrm{T}]^{2}$

http://www.biyolojiegitim.yyu.edu.tr/fizuzaypdf/Evrenin20108S.pdf http://www.biyolojiegitim.yyu.edu.tr/kf/sglayminak/sglayminak.swf

\section{First cluster of the universe/First point of the universe}

In mathematics, a point is a place or a certain position on a plane. it has no dimensions. It is important to understand that a point is not a thing, but a place. An unlimited number of lines pass through any single point.

The first cluster in the universe was in liquid form $\left(10^{390} \mathrm{C}\right)$ and smaller than an atom. It is the first smallest point or cluster of the formation of the universe. The first dark energy, the first dark matter, the first space, the first time, and the buds of the four basic powers in the universe were in this first cluster of universe. Four basic forces in the universe: Gravity (gravity), Weak Nuclear Force (Radioactive Force), Electromagnetic Force and Strong Nuclear Force is the first creature. The first creatures that form together with the buds of these four basic powers are the first cluster of the universe or the first point of the universe; in mathematics it also means the beginning of the objective point and the objective cluster.

In the beginning of the universe; First Dark Energy, then Space Dimension-Four Basic Strength, then Speed Dimension, Time Dimension and Dark Matter are formed.

\section{Speed dimension}

Express unit-time mobility. Speed: The unit time is also taken from the road. It could be an incomplete statement. Because there are ways of accelerating without getting on the road. For example, heartbeat. In the formula of $\mathrm{E}=\mathrm{M} . \mathrm{C}^{2}$ related to the speed of light, interesting results are obtained when $\mathrm{C}$ is infinite and zero is put. The correlation results of the acceleration in the intellectual dimension will be a very important issue in the future. This situation is interesting in relation to intellectual speed. Physicists have talked about tachyon molecules moving faster than the speed of light. Tachyons are considered to have imaginary mass. Tachyons do not appear in the universe. When their energy decreases, their speed increases.

$$
\begin{aligned}
& \mathrm{E}(\text { Energy })=\mathrm{M}(\text { Mass) }) \mathrm{C}^{2} \text { (Light Speed) } \\
& \mathrm{E}=\mathrm{M} .[\mathrm{L}(\text { Space }) / \mathrm{T}(\text { Time })]^{2} \\
& \mathrm{E}=\mathrm{M} .[+\infty,-\infty, \infty \geq, \leq \infty,|\infty|, 0]^{2}
\end{aligned}
$$

http://www.biyolojiegitim.yyu.edu.tr/kf/sgtakion/sgtakion.swf

http://www.biyolojiegitim.yyu.edu.tr/f/everndeisiktanda/ everndeisiktanda.swfhttp://www.biyolojiegitim.yyu.edu.tr/f/bihdhd/ bihdhd.swf

The beginning of the Big Bang Theory; Refers to expanding faster than the speed of light. This situation overlaps with Inflation Theory.

The fate of the rapidly expanding Universe; It overlaps with the Big Rip Theory.

\section{Dimension of forces in the universe}

It contains all the forces in the universe. Our visible universe is 5\% (Matter=light + energy + mass). It includes gravitational force, weak nuclear force, electromagnetic force, and strong nuclear force. $68 \%$ of the universe forms dark energy. The dark matter that forms $27 \%$ of the universe and holds the galaxies together. 
Citation: Demirkuş N, Bilgin EA (2018) A New Approach to the Definitions and Relations of the Concepts of Mathematics, Eternity, Infinity, Death, Time and the First Point. J Biom Biostat 9: 408. doi: 10.4172/2155-6180.1000408

Page 3 of 3

Death: It is the irreversible collapse or change of the creature systems. In short, it is the irreversible change of the creature's system. For example, the death of human, the death of the Universe is Doomsday.

Being: It comes from being. It is actually wrong and defamatory to think of nothingness. Everything is intellectually and figuratively present in wisdom. This is also a potential wisdom. But everything is not transformed into a creature with energy. However, some are shaped as creatures with energy.

Creature: They are living things and inanimate things, created by energy, from the beings realm.

\section{Conclusion}

There are various energy status in the universe. For example, solid, liquid, gas, heat, radiation, sound, wave, light, virtual, intellectual, digital... etc. Energy statuses change towards the future. The temperature variability was between $10^{390} \mathrm{C} /-273^{\circ} \mathrm{C}$. There are 6 basic facts and processes that guide evolution and change in the universe. These are: 1 . Increasingly accelerating, 2 . Increasingly expanding, 3. Cooling increasingly, 4 . Increasingly being buried in the darkness, and 5. Changing areas of gravitation and evolving; It is a universe. 6. A universe of decreasing intensity.

\section{References}

1. Alkan D, Demirkuş N (2014) A Brand New Approach To Set, Zero, Infinite Eternity And Various Other Mathematical And Scientific Concepts.International Eurasian Conference on Mathematical Sciences and Applications.

2. Demirkuş N, Alkan D (2017) A Brand New Approach To Sets in Mathematics Education. International Conference on Mathematics and Mathematics Education (ICMME-2017), Harran University Şanlıurfa, 11-13 May 2017.

3. Demirkuş N, Gülen S (2017) Popüler Fizik Kavramları İçeren Görsel Ders Materyali Geliştirme Çalışması. Yüzüncü Yıl Üniversitesi Eğitim Fakültesi Dergisi14: 320-338.

4. Wald RM (1992) Space, time, and gravity: the theory of the big bang and black holes: University of Chicago Press.

5. Eire CMN (2010) In A Very Brief History of Eternity.Princeton University Press 2010.

6. Marty ME (2011) A Very Brief History of Eternity. Church History 80: 227-229.

7. Yarbrough J (2015) Philip the Chancellor on the Beginning of Time. Vivariuman International Journal for the Philosophy and Intellectual Life of the Middle Ages and Renaissance 53: 1-25.

8. Mac Cannell JF (2009) Eternity or infinity? Badiou's Point. Environment and Planning D-Society \& Space 27: 823-839.

9. Minecan AMC (2017) Time and Annihilation: Issues Concerning the Aristotelian Legacy in the Thomist Vision of Temporality. Themata-Revista De Filosofia 55: 177-196. 